\title{
¿QUÉ DEBEN SER LAS POLÍTICAS PÚBLICAS INTERCULTURALES?
}

Edwin Cruz Rodríguez ${ }^{[1]}$

\section{Resumen}

Con frecuencia, las políticas interculturales se confunden con las acciones afirmativas de cuño multicultural. No obstante, ambas concepciones tienen supuestos y efectos distintos. Este trabajo establece las diferencias entre ellas desde una perspectiva normativa. La proposición principal es que la acción afirmativa permite conseguir mayores grados de equidad entre grupos culturales, pero es insuficiente para lograr los ideales del interculturalismo: el diálogo, el respeto, la convivencia, el aprendizaje mutuo entre culturas, y la eliminación de las causas estructurales que producen la desigualdad entre ellas. Por consiguiente, es necesario avanzar hacia una concepción distinta de políticas interculturales.

Palabras clave: Multiculturalismo; interculturalidad; justicia; acción afirmativa; políticas interculturales.

\section{Summary}

Frequently, intercultural policies are confused with affirmative actions of multicultural stamp. However, both conceptions have different assumptions and effects. This research establishes the differences between both views from a normative perspective. The main proposal is that affirmative action allows achieving greater equity between cultural groups, but is insufficient to achieve the ideals of interculturalism, which includes: dialogue, respect, coexistence, mutual learning between cultures, and the elimination of the structural causes that produces inequality between them. Therefore it is necessary to advance to a different conception of intercultural policies.

Keywords: Multiculturalism; interculturality; justice; affirmative action; intercultural policies.

\section{Introducción}

El campo de estudio de las políticas públicas se erigió mediante el establecimiento de fronteras respecto de otras formas de estudiar los fenómenos políticos. Las "ciencias de las políticas" se ocuparían del estudio de las políticas y una de estas fronteras se estableció respecto al estudio del "deber ser". Así por ejemplo, Charles Lindblom (1999) sostuvo que esta disciplina debía avocarse al estudio del "ser" de los fenómenos

[1] Candidato a doctor en estudios políticos Universidad Nacional de Colombia. ecruzr@unal.edu.co 
y, particularmente, del cambio sociopolítico incremental, dejando a la filosofía política la tarea de dilucidar las formas más justas de organización social. Sin embargo, las políticas públicas están atravesadas por distintos horizontes normativos que confieren sentido a las acciones de los actores que en ellas toman parte. No en vano, en su obra clásica Meny y Thœnig (1992: 89, 96) definen las políticas públicas en un sentido descriptivo como el programa de acción de las autoridades públicas, pero también desde el punto de vista prescriptivo o normativo como una teoría del cambio social.

Las "políticas interculturales", un tipo particular dentro de las políticas de las diversidades (Torres, 2010), tienen una relación más estrecha con el ámbito de lo normativo, puesto que su razón de ser es garantizar la justicia entre grupos culturales en el interior de un Estado. En este sentido, pueden distinguirse dos concepciones de justicia intercultural: por una parte, el multiculturalismo implementado en las democracias anglosajonas y fundamentado por Kymlicka (1996); por otra, el interculturalismo latinoamericano, cuyo origen se remonta, precisamente, a la lucha de los movimientos indígenas por el reconocimiento de su diferencia.

Aunque frecuentemente las políticas interculturales se confunden con las acciones afirmativas de cuño multicultural, ambos enfoques tienen fundamentos y consecuencias distintas. Este trabajo establece las diferencias entre ambas concepciones desde una perspectiva normativa. La proposición principal es que las acciones afirmativas permiten conseguir mayores grados de equidad entre grupos culturales, pero son insuficientes para conseguir los ideales del interculturalismo: el diálogo, el respeto, la convivencia, el aprendizaje mutuo entre culturas, y la eliminación de las causas estructurales que producen la desigualdad entre ellas. Por consiguiente, es necesario avanzar hacia una concepción distinta de políticas interculturales.

\section{Atacar la dominación cultural}

Las políticas de acción afirmativa están basadas, al igual que el multiculturalismo defendido por Kymlicka, en la distinción entre grupos culturales minoritarios y mayoritarios. El multiculturalismo supone que los grupos culturales minoritarios siempre van a estar subordinados en regímenes democráticos, donde las mayorías deciden (Kymlicka, 1996: 13). Por lo tanto, se requieren derechos diferenciados y acciones afirmativas para los grupos minoritarios que corrijan las desigualdades que enfrentan sus miembros individuales. Por ejemplo, se requieren cuotas en las instituciones políticas y educativas focalizadas en los grupos minoritarios.

Si bien esa perspectiva puede ser idónea en contextos como las democracias anglosajonas como Canadá, caso en que se inspira Kymlicka, donde la desigualdad entre distintos grupos culturales está vinculada a su tamaño, no resulta muy convincente en casos como América Latina, donde las injusticias y desigualdades entre grupos culturales no se explica necesariamente por su tamaño. Para no ir muy lejos, en países 
como Bolivia y Guatemala la mayoría de la población se adscribe a determinadas culturas indígenas. Empero, la historia republicana de estos países está marcada por la dominación de una élite minoritaria, autoconcebida como blanca o mestiza, que se abrogó el derecho de definir los contenidos del imaginario nacional.

Por esa razón, el interculturalismo abandona el criterio del tamaño del grupo cultural y, en el caso específico de América Latina, propone centrarse en la dominación cultural producto del legado colonial. Así por ejemplo, Quijano (2000) y Walsh (2009: 28) sostienen que las injusticias entre grupos culturales se originan por la "colonialidad": un patrón de poder global, heredado de la dominación colonial o colonialismo propiamente dicho, que implica el gobierno de un Estado extranjero, que jerarquiza poblaciones basado en la idea de "raza".

Existen sociedades pluriculturales, e incluso plurinacionales, que están dominadas por estados monoculturales. En muchos de los países latinoamericanos, las élites blancas o mestizas han copado los lugares de poder y los estratos sociales altos, mientras que las antiguas "castas" de la Colonia, indígenas y afrodescendientes, están confinados a los estratos bajos y excluidos del ejercicio del poder público (Walsh 2009: 125).

Las consecuencias de ambos enfoques para las políticas públicas son considerables. Las acciones afirmativas son medidas de carácter temporal implementadas por el Estado para tratar desigualdades históricamente acumuladas, garantizar la igualdad de oportunidades o compensar costos provocados por la discriminación de determinados grupos, por motivos étnicos, religiosos, sexuales o de género, entre otros (Mosquera, et al., 2009: 76). Así, la acción afirmativa puede ser eficaz para conseguir la equidad entre los individuos miembros de grupos culturales discriminados donde sea posible focalizarlos, es decir, donde constituyan una minoría claramente identificable. Sin embargo, su eficacia disminuye donde la mayoría de la población constituye una cultura subordinada, como en los casos antes mencionados. Ello se explica porque en estos casos no es posible focalizar claramente la población objeto y la acción afirmativa, por definición, no puede dirigirse a la mayoría de la población. En estos casos, se requieren otro tipo de medidas, orientadas al cambio estructural y a hacer equitativas las relaciones entre las culturas más que a integrar la cultura subordinada mayoritaria a los valores y formas de ser de la cultura dominante minoritaria.

\section{Promover acciones transformativas e igualdad sustancial}

Mientras la acción afirmativa está orientada a corregir las consecuencias de la desigualdad entre culturas (la discriminación, la exclusión), apuntando a mejorar la igualdad de oportunidades, las políticas interculturales apuestan por atacar las causas de tal desigualdad, propugna por una igualdad sustancial que implica transformaciones estructurales para eliminar las inequidades sociales y económicas que impiden un diálogo equitativo entre culturas. 
Kymlicka (1996: 15-16) discute con el supuesto liberal individualista según el cual para gestionar la diversidad cultural son suficientes los derechos individuales, pues la igualdad se entiende como iguales derechos para los individuos. Para Kymlicka, (1996: 157) el Estado no puede ser neutral frente a las identidades étnicas y nacionales. En una democracia, las decisiones que el Estado adopta para tratar la diversidad cultural hacen que privilegie sistemáticamente la cultura mayoritaria (Kymlicka 1996: 80). Además, los liberales individualistas ignoran que los miembros de las minorías nacionales enfrentan desventajas que no afectan a la mayoría (Kymlicka 1996 156). Por consiguiente, la imparcialidad no consiste en tratar todas las culturas como si fuesen iguales, sino en conceder a las minorías nacionales las mismas oportunidades que a la mayoría, mediante derechos diferenciados de grupo y acciones afirmativas. Así se hacen más equitativas las relaciones entre culturas y se satisface un principio de justicia según el cual "todos los grupos nacionales tienen la posibilidad de mantenerse como cultura distinta, si así lo desean” (Kymlicka, 1996: 160).

En esta vena, las acciones afirmativas tratan de forma desigual a los grupos e individuos, para compensar, eliminar o cambiar, las prácticas que conllevan a la desigualdad y la discriminación, y de esa forma asegurar la igualdad (Cortez, 2011: 285-286). Sin embargo, no pueden confundirse con políticas para erradicar la pobreza o conseguir una igualdad material sustancial; son medidas para asegurar la igualdad de oportunidades. Para ello comprenden incentivos que tratan de disminuir las desventajas sociales, políticas y económicas como las becas, cuotas o subvenciones, que igualmente realizan un tratamiento desigual para favorecer el grupo desfavorecido (Mosquera, et al. 2009: 81). En tal sentido, se rigen por criterios primordialmente cuantitativos.

La igualdad entre culturas por la que propugna la interculturalidad va más allá de la igualdad formal y el reconocimiento de derechos. Para Walsh (2009: 43-44) la interculturalidad implica cambios estructurales. No se reduce a tolerar la diferencia dentro de las estructuras de la colonialidad establecidas, sino involucra profundas transformaciones, distribución del poder político y socioeconómico, que combatan la desigualdad entre culturas (Tubino, 2007a: 195-196). Como sostienen Viaña, Claros y Sarzuri (2009: 7) la interculturalidad, el problema de la convivencia entre culturas en términos igualitarios, no es un problema de "voluntad subjetiva", como lo pretende muchas veces el multiculturalismo, sino también de constricciones estructurales, políticas, económicas y sociales, que condicionan tales relaciones. En consecuencia, no es posible separar la justicia cultural de la justicia social.

Así, las políticas interculturales permiten articular las acciones por la justicia social con la necesidad del reconocimiento de la diferencia. De acuerdo con Tubino (2007a: 195-196): 


\section{GÉNERO E INTERCULTURALIDAD}

El multiculturalismo anglosajón formula y busca remediar el problema de la injusticia cultural como si fuera un problema aislado y aislable. Por ello promueve la sustitución de las políticas asimilacionistas de los Estados nacionales monoculturales por políticas de reconocimiento de las identidades, sin cuestionar el modelo económico vigente. Por el contrario, el interculturalismo latinoamericano se plantea el problema de la injusticia como un problema ligado al problema de la pobreza y la exclusión social. La injusticia cultural, sostenemos, no es sino la otra cara de la injusticia económica. Por lo tanto, si la exclusión económica y la discriminación cultural son dos fenómenos estrechamente interconectados, entonces las políticas de reconocimiento deben estar forzosamente acompañadas de políticas redistributivas.

Allí donde la mayoría de la población constituye una cultura subordinada se requieren, más que acciones focalizadas, cambios estructurales que eliminen las causas de la inequidad. Así pues, es necesario complementar las acciones afirmativas con "acciones transformativas", que no sólo ataquen las consecuencias de las relaciones asimétricas entre culturas en el corto plazo sino sobre todo sus causas en el largo plazo (Tubino, 2011: 13). Nancy Fraser (1997: 38), distingue las acciones afirmativas de las "acciones transformativas" de la siguiente manera:

Con soluciones afirmativas a la injusticia me refiero a aquellas soluciones dirigidas a corregir los resultados inequitativos de los acuerdos sociales, sin afectar el marco general que los origina. Por soluciones transformativas, por el contrario, entiendo aquellas soluciones dirigidas a corregir los resultados inequitativos, precisamente mediante la reestructuración del marco general implícito que los origina. El punto esencial del contraste es resultados finales versus procesos que los generan, no el cambio gradual versus el apocalíptico.

En suma, las acciones positivas se orientan a gestionar las consecuencias de la discriminación, la exclusión o la opresión, mientras las políticas interculturales tratan de modificar el contexto social y estructural que las origina, sus causas.

\section{Apostar por respeto y convivencia, más que por coexistencia y tolerancia}

Mientras las acciones afirmativas buscan la coexistencia, las políticas interculturales deben apostar a la convivencia y el diálogo entre culturas.

El multiculturalismo se propone "acomodar" las diferencias nacionales y étnicas "de una manera estable y moralmente defendible" (Kymlicka 1996: 46). Así planteado, el multiculturalismo apuesta por la tolerancia y la coexistencia entre culturas. La tolerancia implica "soportar lo diferente" (Tubino, 2003: 2). Ello quiere decir que la existencia del otro, lo mismo que el diálogo y el intercambio entre culturas, no se 
conciben como un bien en sí mismos; en algunos casos se entienden como un mal menor o en todo caso como algo no deseable. En consecuencia, las culturas pueden coexistir, pero de forma aislada, sin convivir. Tolerancia y coexistencia no suponen necesariamente el diálogo o intercambio entre culturas.

El concepto de interculturalidad también apunta a relaciones equitativas entre culturas, pero enfatiza en los intercambios y el aprendizaje mutuo entre ellas. Interculturalidad significa "el contacto e intercambio entre culturas en términos equitativos; en condiciones de igualdad" (Walsh 2009: 14). Las relaciones y el aprendizaje tienen lugar cotidianamente donde existe diversidad cultural, pero en condiciones de desigualdad. La interculturalidad es un proyecto descolonizador: propugna porque desaparezca toda desigualdad entre culturas (Walsh, 2009: 54). Ello no implica erradicar los conflictos entre culturas, sino actuar sobre las estructuras que producen la diferencia como desigualdad y construir puentes de interrelación entre ellas (Walsh, 2009: 46)

Se trata de romper con las relaciones de subordinación entre culturas para garantizar un "con-vivir" en condiciones de respeto mutuo. La interculturalidad "no tiene la pretensión de asumir la perspectiva del otro sino de permitir que la diferencia intervenga en uno, abriendo así nuevas perspectivas interculturales de vivir 'con' o 'con-vivir"' (Walsh, 2009: 15). Es un enriquecimiento mutuo entre culturas que no implica diluir la identidad de los interlocutores para formar una síntesis única.

En contraste con el multiculturalismo, el interculturalismo apuesta por el respeto y la convivencia entre culturas. La tolerancia multicultural no necesariamente implica diálogo y convivencia entre culturas. En cambio, el concepto de respeto implica que el intercambio con otras culturas y la convivencia son un bien en sí mismos y, por lo tanto, son deseables. Como sostiene Tubino (2005a: 94), el multiculturalismo trata de producir sociedades paralelas, mientras la interculturalidad busca producir sociedades integradas y relaciones simétricas entre culturas: "las políticas multiculturales evitan los desencuentros. Las políticas interculturales promueven los encuentros. El multiculturalismo promueve la tolerancia, el interculturalismo el diálogo". El respeto no sólo conlleva la convivencia entre culturas, sino que promueve la necesidad de hacer equitativas tales relaciones a fin de conseguir el reconocimiento. De acuerdo con Tubino (2003: 10), "reconocer al otro es respetar su autonomía, es percibirlo como valioso. Pero la valoración a priori del otro es un falso reconocimiento. La gente merece y desea respeto, no condescendencia. El verdadero reconocimiento es a posteriori, se da en la experiencia del encuentro con el otro. Pero sólo es posible en relaciones auténticamente simétricas y libres de coacción".

La acción afirmativa se enfoca en la igualdad entre grupos, descuidando el intercambio y el mutuo aprendizaje, ideales de la interculturalidad. Aún más, su objetivo es favorecer la integración de los individuos o grupos discriminados, en igualdad de 
condiciones, a la sociedad o cultura mayoritaria. De ahí su carácter temporal y de corto plazo, pues se supone que en algún momento, cuando estos sujetos se integren y se supere la situación de discriminación, dejarán de ser necesarias. En otras palabras, las acciones afirmativas pretenden avanzar hacia una sociedad "ciega en materia de color" o pertenencia étnica, donde tales acciones no serían necesarias (Kymlicka 1996: 16-17).

Además, las acciones afirmativas son políticas principalmente para la equidad, no para la interculturalidad. Aunque mejoran la igualdad de oportunidades e introducen en la agenda pública temas de discriminación, generan tensiones que no necesariamente llevan a mejores formas de convivencia (Tubino 2007b: 91). Por ejemplo, las políticas de educación para grupos étnicos, aunque reconozcan derechos en el marco de las políticas de reconocimiento, contribuyen a la reproducción de representaciones racistas sobre poblaciones indígenas y negras (Rojas y Castillo 2007: 12).

Ello se explica principalmente porque están focalizadas exclusivamente en los grupos desfavorecidos o las culturas minoritarias, cuando el problema de la inequidad en las relaciones compete a ambos. La discriminación es una relación, si hay discriminados es porque hay discriminadores (Tubino 2005a: 90). Por lo tanto, para combatir la discriminación no sólo se deben hacer políticas para los discriminados, sino también para los discriminadores.

En fin, las acciones afirmativas son eficaces en promover el acceso de los excluidos a espacios de donde han sido discriminados. Sin embargo, ello no implica que la discriminación desaparezca. La hace visible, pero también puede reforzarla. Como afirma Fidel Tubino, no es suficiente con fortalecer la identidad de los excluidos o discriminados, es necesario trabajar en mejorar las relaciones entre culturas, la convivencia y no sólo la coexistencia:

Para que haya discriminación tiene que haber alguien que discrimina y alguien que es discriminado, alguien que estigmatiza y alguien que es estigmatizado. No basta con el fortalecimiento de la identidad de los discriminados para acabar con la discriminación; hay que cambiar las representaciones inconscientes sobre las cuales se han instalado patrones perversos de relación intercultural. Y digo "perversos" porque se trata de relaciones que generan expectativas que no están en condiciones de satisfacer, que no pueden dar lo que ofrecen. Ofrecen reconocimiento y no lo otorgan ni a discriminados ni a discriminadores. Los discriminados no son reconocidos porque no son ni respetados ni valorados en su identidad. Y los que discriminan obtienen un reconocimiento forzado, falso, porque para ellos, los discriminados no son personas, son cosas, medios. Y el reconocimiento es, por definición, recíproco (2007b: 96).

No se trata de uniformizar las culturas, sino de preparar sus miembros individuales para la interacción en condiciones de respeto recíproco. Ello pasa por la construcción 
de un espacio neutral de relación entre culturas, una cultura pública común abierta a todas las diferencias, cuyos criterios sean acordados con base en el diálogo y en el consenso entre los diferentes grupos culturales, más que en la imposición de los valores de la cultura dominante.

La Educación Intercultural Bilingüe (EIB) constituye un claro ejemplo de las limitaciones de la acción afirmativa para construir la convivencia entre culturas. De acuerdo con Donoso et al. (2006: 25-27), la EIB, al formularse como una educación para grupos específicos, tiene dificultades para que los estudiantes allí socializados convivan con otros grupos en otros contextos. El discurso de la educación intercultural trata de generar una pedagogía de la diversidad para permitir el desarrollo de los pueblos indígenas y una coexistencia social armónica. Pero en la práctica se focaliza en lo indígena y, en vez de buscar la convivencia de las diversidades, pretende que los pueblos indígenas se integren a la sociedad nacional como ciudadanos abstractos.

\section{Fomentar el diálogo y la participación}

Las acciones afirmativas están orientadas "desde arriba". Por ello, pese a que contribuyen a disminuir las brechas sociales, crean vínculos de dependencia que coartan la autonomía de las personas (Tubino, 2003: 6). Su defecto es que aunque aportan a la inclusión de los excluidos no los prepara para la interacción cultural, no forma ciudadanos capaces de desenvolverse en contextos culturales hostiles (Tubino, 2007b: 92). Las políticas interculturales deben ser políticas participativas "desde abajo", que permitan un fortalecimiento de la sociedad civil y el diálogo entre las distintas culturas a fin de definir sus criterios. La interculturalidad, el diálogo en condiciones de respeto y convivencia con aprendizaje mutuo, es tanto un presupuesto de partida, como una consecuencia de las políticas interculturales.

El objetivo es que la formulación misma de las políticas convoque el diálogo intercultural, no que se formulen e implementen verticalmente desde el Estado. Lo deseable es que exista un proceso de discusión y diálogo intercultural para definir las necesidades y anhelos de las poblaciones comprometidas en las políticas. El carácter participativo de las políticas interculturales alude al hecho de que no se pueden diseñar políticas sin preguntarle al otro sobre sus propias necesidades, deseos y sentires. El diálogo intercultural es una alternativa a la imposición de valores monoculturales.

De acuerdo con Tubino (2003: 11), existen dos formas de concebir el diálogo intercultural: "como imagen ideal o como utopía realizable". En su primera acepción, implica terminar con los conflictos entre culturas y alcanzar una convivencia armónica. No obstante, esta perspectiva además de su naturaleza inevitable, desconoce el carácter dinamizador y enriquecedor del conflicto. Los intentos por alcanzar reconciliaciones definitivas entre los diferentes terminan por generar imposiciones autoritarias. Por tanto, el diálogo intercultural no debe apostar por la eliminación de los conflictos, sino 
porque sean manejados de forma razonable, que se haga de los conflictos un aspecto enriquecedor de los grupos e individuos que conforman las culturas. Es, en últimas, concebir el diálogo más como un proceso permanente que como un resultado definitivo, aceptar el proceso mismo como un horizonte abierto donde se está dispuesto a convencer y ser convencido.

En fin, y siguiendo a Tubino (2009 156), a diferencia de las perspectivas basadas en el consenso, que tratan de generar acuerdos entre las distintas "doctrinas comprehensivas" o concepciones del bien, sin modificarlas, el diálogo intercultural genera cambios en dichas concepciones, valores y tradiciones de las personas y grupos. No se orienta a conseguir un consenso último sobre los principios que garantizarían la coexistencia, sino a forjar en el proceso formas de "convivencia razonable". Esta perspectiva privilegia el proceso mismo del diálogo, como un generador de convivencia intercultural, antes que los principios o criterios reguladores a los que se arribe, pues tales principios o criterios siempre podrán ser modificados de forma dialógica.

Esos supuestos contribuyen a fundamentar la hermenéutica diatópica como una forma de adelantar el diálogo intercultural. Esta perspectiva supone una interpretación de la relación intercultural basada en la apertura del horizonte y, concretamente, en la ubicación entre los dos lugares o topoi de las culturas. Es un procedimiento que responde a la pregunta de cómo entender los valores y concepciones de una cultura desde el topos, los valores y concepciones, de otra. Ello implica intentar situarse entre ambas, de ahí su carácter diatópico (dos lugares):

Por hermenéutica diatópica entiendo una reflexión temática sobre el hecho de que el loci (topoi) de culturas históricamente, ajenas hace problemático entender una tradición con las herramientas de otra, y el intento hermenéutico para superar esos golfos (Panikkar, 1982: 77).

Su objetivo es "crear juntos nuevos horizontes de inteligibilidad recíproca, sin que pertenezcan de manera exclusiva a una cultura” (Anguiló, 2010: 155).

Toda interpretación de otra cultura siempre estará incompleta, pues la otredad, en un sentido epistemológico, sólo es parcialmente accesible. Es imposible ver con los ojos que otro ve, o en términos de la hermenéutica diatópica, asumir por completo el topoi de la otra cultura. No obstante, como anteriormente se afirmó, el intento forja una empatía que modifica los valores y concepciones de ambos interlocutores y conlleva la formulación de acuerdos parciales de convivencia.

Según Santos (2002: 70), el diálogo intercultural se produce entre culturas diferentes que albergan sentidos incontrastables. Cada uno tiene entramados (topoi) fuertes, los cuales funcionan como lugares comunes o premisas para la argumentación y hacen posible la discusión, el intercambio de argumentos. Pero una condición para 
la interpretación es asumir el carácter incompleto de las culturas. Esta incompletud sólo puede apreciarse desde la perspectiva del otro, pues el punto de vista propio está marcado siempre por la intención de erigir su propia identidad como la identidad de la totalidad, su parte como el todo. De ahí que:

El verdadero punto de partida de este diálogo es un momento de descontento con la propia cultura, una sensación difusa de que la propia cultura no proporciona respuestas satisfactorias a mis dudas, perplejidades o expectativas. Esta sensibilidad difusa está vinculada a un saber vago y a una curiosidad inarticulada acerca de otras culturas posibles y sus respuestas. El momento de descontento incluye un entendimiento previo de la existencia y posible relevancia de otras culturas, y se traduce a una conciencia reflexiva de la incompletud cultural. El impulso colectivo o individual para un diálogo intercultural y, de ese modo, para la hermenéutica diatópica, empieza aquí (Santos 2002: 78).

El objetivo de la hermenéutica diatópica no es llegar a la completud, siempre inalcanzable, sino aumentar la conciencia de la incompletud entre los interlocutores. Para Santos (2002: 79), el progreso de la hermenéutica diatópica debería medirse en relación al grado en que hace que las culturas tomen conciencia de su incompletud. Es una conciencia autorreflexiva que "significa el reconocimiento en el diálogo de la incompletud cultural de la propia cultura como es vista en el espejo de la incompletud cultural de la otra".

\section{Pensar en el largo plazo}

Finalmente, las acciones afirmativas son de corto plazo y temporales; muchas veces tienen una función "analgésica", para canalizar el malestar que produce la inequidad social entre culturas (Tubino, 2005b: 56). Ello tiene que ver con su sesgo asimilacionista. Reconocen al otro discriminado como desigual y por ello se orientan a mejorar la igualdad de oportunidades para que pueda acceder a los espacios que le están vedados. Pero no lo reconocen como diferente, lo que requiere afirmar su diferencia al tiempo que se propende por alcanzar la equidad en las relaciones con miembros de otras culturas.

A diferencia del multiculturalismo de Kymlicka, cuyo criterio de justicia, como anteriormente se mencionó, es permitir que las culturas mantengan y desarrollen su cultura si así lo desean, el interculturalismo apuesta por un criterio de justicia basado en el reconocimiento del otro como igual y diferente al mismo tiempo. Las transformaciones estructurales orientadas a eliminar las causas de la desigualdad entre culturas no sólo son necesarias para que cada cultura mantenga su diferencia, sino también para un reconocimiento del otro como sujeto, como igual y al mismo tiempo diferente (Walsh 2009: 45). Este es el criterio de justicia entre culturas por el que apuesta el interculturalismo. 
Reconocer a la otra cultura sólo como igual puede equivaler a desconocer su particularidad y tomarla como idéntica a la cultura propia (asimilacionismo). Pero reconocerla solamente como diferente puede generar una relación de desigualdad entre culturas (Todorov, colonialidad, 2010: 293). Una relación justa implica reconocer la otra cultura como igual y diferente. No es suficiente con el criterio de justicia del multiculturalismo, permitir que una cultura conserve su particularidad si así lo desea, pues ello es compatible con una relación de desigualdad entre culturas. Una cultura subordinada puede mantener su especificidad sin que ello implique una relación equitativa con otras culturas, por ejemplo, en el régimen de castas indio. Una relación justa implica reconocer la otra cultura como igual y diferente a la cultura propia en forma simultánea.

Las acciones afirmativas propugnan por la igualdad entre culturas, pero no resaltan las diferencias. Su objetivo es hacer que los grupos culturales desfavorecidos se integren en igualdad de condiciones a la cultura mayoritaria, avanzando hacia una sociedad donde no es necesario el trato diferenciado a lo que es diferente, más que favorecer el desarrollo de la diversidad.

En contraste, las políticas interculturales suponen un reconocimiento de la diferencia en forma permanente. Por eso, deberían operar permanentemente. Una vez se mitigue inequidad entre grupos culturales, se requieren políticas que salvaguarden la diversidad cultural y preparen los distintos grupos para la interacción, para prevenir la opresión y la discriminación. Así se atenúa su sesgo integracionista. En fin, según Tubino (2005a: 94), las políticas interculturales son de largo plazo. Buscan transformar las estructuras simbólicas donde se desenvuelven las relaciones entre diferentes.

\section{Corolario}

Las acciones afirmativas, inspiradas en el enfoque multicultural y las políticas interculturales no son mutuamente excluyentes. Por el contrario, las acciones afirmativas pueden contribuir a la equidad, el diálogo y la convivencia entre culturas además de complementar los derechos diferenciados en función del grupo necesarios para garantizar la justicia entre ellas. Más aún, por las limitaciones de recursos o de legitimidad, en algunos casos son las únicas alternativas posibles.

Sin embargo, desde la perspectiva intercultural la eficacia de la acción afirmativa es ambigua. Existen coincidencias entre ambas, pues buscan corregir las inequidades entre grupos culturales. No obstante, las acciones afirmativas son necesarias pero no suficientes para alcanzar los ideales de la interculturalidad, el respeto, la convivencia, el diálogo y el aprendizaje mutuo entre grupos culturales.

En consecuencia, se requiere un tránsito hacia las políticas interculturales, que ataquen las causas socioeconómicas de la desigualdad más allá de sus consecuencias; 
que no sólo se preocupen por suprimir la discriminación y facilitar la integración de los grupos culturales a la cultura dominante, sino que permitan el desarrollo de sus diferencias; que, en términos normativos, vayan más allá de la tolerancia y la coexistencia para alcanzar el respeto y la convivencia entre culturas; que involucren las diferentes culturas en su diseño e implementación en procesos dialógicos y participativos que funcionen a largo plazo o de forma permanente.

\section{Lista de referencias}

Anguiló, J. (2010). Hermenéutica diatópica, localismos globalizados y nuevos imperialismos culturales. Cuadernos Interculturales. Volumen 8.

Cortez, Olivia (2011). Acciones afirmativas para afrodescendientes: ¿un reconocimiento de justicia o redistribución de recursos? En J. Sánchez, V. Avendaño y D. Caicedo (eds.) Pueblos afrodescendientes y derechos humanos. Del reconocimiento a las acciones afirmativas. Quito: Ministerio de Justicia, Derechos Humanos y Cultos del Ecuador-Oficina del Alto Comisionado de las Naciones Unidas para los Derechos Humanos, 2011: 283-315.

Donoso Andrés, Rafael Contreras, Leonardo Cubillos y Luis Aravena (2006). Interculturalidad y políticas públicas en Educación. Estudios pedagógicos 1: 21-31.

Fraser, Nancy (1997). Iustitia interrupta. Bogotá: Universidad de los Andes.

Kymlicka, Will (1996). Ciudadanía multicultural. Buenos Aires: Paidós.

Lindblom, Charles (1999). Democracia y sistema de mercado. México: FCE.

Meny Ives y Jean-Claude Thœnig (1992). Las políticas públicas. Barcelona: Ariel.

Mosquera, Claudia; Margarita Rodríguez y Ruby León (2009). Las acciones afirmativas como medio de inclusión social. Énfasis conceptuales, polémicas frecuentes y experiencias de implementación en algunos países. En: Claudia Mosquera y Ruby León (eds.) Acciones afirmativas y ciudadanía diferenciada étnico-racial negra, afrocolombiana, palenquera y raizal. Bogotá: Universidad Nacional de Colombia, 2009: 69-152.

Panikkar, Raimon (1982). Is The Notion of Human Rights a Western Concept?. Diogenes 75: 75-102.

Quijano, Aníbal (2000). Colonialidad del poder y clasificación social. Journal of WorldSystems Research 2: 342-386. 
Rojas, Axel y Elizabeth, Castillo (2007). Multiculturalismo y políticas educativas en Colombia ¿interculturalizar la educación?. Revista Educación y Pedagogía 48: 11-24.

Santos Boaventura de Souza (2002). Hacia una concepción multicultural de los derechos humanos. El Otro derecho 28: 59-83.

Todorov, Tzvetan (2010). La conquista de América. El problema del otro. México: Siglo XXI.

Torres, Víctor (2010). La acción pública intercultural. Abya Yala: Quito.

Tubino, Fidel (2003). Interculturalizando el multiculturalismo. Barcelona: CIDOB.

Tubino, Fidel (2005a). La praxis de la interculturalidad en los estados nacionales latinoamericanos. Cuadernos interculturales 5: 83-96.

Tubino, Fidel (2005b). Entre el multiculturalismo y la interculturalidad: más allá de la discriminación positiva. En: Norma Fuller (Ed.) Interculturalidad y política: desafíos y posibilidades, 2005b: 51-76. Lima: RDCSP.

Tubino, Fidel (2007a). El interculturalismo frente a los desafíos del pluralismo jurídico. En: Caminos para la inclusión en la educación superior. Lima: Fondo editorial Fundación EQUITAS e IEP, 2007a: 190-209.

Tubino, Fidel (2007b). Las ambivalencias de las acciones afirmativas. En: VVAA Educar en ciudadanía intercultural. Lima: Universidad de la Frontera y Pontificia Universidad Católica del Perú, 2007b: 91-110

Tubino, Fidel (2009). Aportes de la hermenéutica diatópica al diálogo intercultural sobre los derechos humanos. En C. Monteagudo, F. Tubino (eds.) Hermenéutica en Diálogo. Ensayos sobre alteridad, lenguaje e interculturalidad. Lima: OEAOEI-PUCP, 2009: 55-179.

Tubino, Fidel (2011). El nivel epistémico de los conflictos interculturales. Revista electrónica construyendo nuestra interculturalidad 6-7: 1-14.

Viaña Jorge, Claros Luis y Sarzuri Marcelo (2009). Presentación. En VVAA, Interculturalidad crítica y descolonización. Fundamentos para el debate. La Paz: Instituto Internacional de Integración del Convenio Andrés Bello, 2009: 7-8.

Walsh, Catherine (2009). Interculturalidad, Estado, Sociedad. Luchas (de)coloniales de nuestra época. Quito: Universidad Andina Simón Bolívar-Abya-Yala. 